\title{
Ácidos graxos polinsaturados no sangue de gestantes suplementadas com ômega-3 e óleo de linhaça dourada
}

\author{
Polyunsaturated fatty acids in the blood of pregnant women who have \\ consumed omega-3 supplements and golden flaxseed oil
Les acides gras poly-insaturés dans le sang des femmes enceintes complétées avec oméga-3 et de l'huile de graines de lin d'or

Ácidos grasos poliinsaturados en la sangre de mujeres embarazadas suplementadas con omega-3 y el aceite de linaza de oro

\author{
Leila Simone Foerster Merey ${ }^{1}$ \\ Durval Batista Palhares ${ }^{1}$ \\ Karla Rejane de Andrade Porto ${ }^{2}$ \\ Karla de Toledo Candido Muller ${ }^{3}$
}

Recebido em 25/05/2017; revisado e aprovado em 25/07/2017; aceito em 25/07/2017

DOI: http://dx.doi.org/10.20435/inter.v19i4.1615

\begin{abstract}
Resumo: O objetivo deste estudo foi avaliar os níveis séricos de docosahexaenóico (DHA) e eicosapentaenoico (EPA) no sangue de gestantes que receberam suplementação de ômega 3 através da ingestão de cápsulas ou óleo de linhaça. Comparando os grupos, houve maior nível para o óleo de linhaça para os conteúdos de AA e DHA, indicando que a suplementação favoreceu a rota metabólica da formação e dos intermediários eicosanoides.
\end{abstract}

Palavras-chave: Linum usitatissimun; eicosanoides; metabolismo.

\begin{abstract}
The objective of this study was to evaluate serum levels of docosahexaenoic (DHA) and eicosapentaenoic (EPA) in the blood of pregnant women who received omega 3 supplementation through ingestion of capsules or linseed oil. Comparing the groups, there was a higher level for flax oil for AA and DHA contents, indicating that supplementation favored the metabolic pathway of both eicosanoid intermediates formation.
\end{abstract}

Keywords: Linum usitatissimun; eicosanoids; metabolism.

Résumé: L'objectif de cette étude était d'évaluer les taux sériques de docosahexaénoïque (DHA) et l'eicosapentaénoïque (EPA) dans le sang des femmes enceintes qui ont reçu des suppléments d'apport en oméga-3 à capsules ou l'huile de lin. En comparaison entre les groupes était plus haut niveau à l'huile de lin pour l'AA et de teneur en DHA, ce qui indique que la supplémentation a favorisé la formation de l'une des voies métaboliques intermédiaires de eicosanoïdes.

Mots-clés: Linum usitatissimun; eicosanoïdes; métabolisme.

Resumen: El objetivo de este estudio fue evaluar los niveles séricos de docosahexaenoico (DHA) y eicosapentaenoico (EPA) en la sangre de mujeres embarazadas que recibieron suplementación de la ingesta de ácidos grasos omega-3 a través de cápsulas o aceite de linaza. La comparación entre los grupos fue mayor nivel para el aceite de linaza para el AA y el contenido de DHA, lo que indica que la suplementación favoreció la formación de vía metabólica de eicosanoides intermedios.

Palabras clave: Linum usitatissimun; eicosanoides; el metabolismo.

\footnotetext{
${ }^{1}$ Universidade Federal de Mato Grosso do Sul, Campo Grande, Mato Grosso do Sul, Brasil.

2 Faculdade de Campo Grande, Campo Grande, Mato Grosso do Sul, Brasil.

${ }^{3}$ Universidade Católica Dom Bosco, Campo Grande, Mato Grosso do Sul, Brasil.
} 


\section{INTRODUÇÃO}

A tendência nutricional da atualidade preconiza uma alimentação saudável, composta por alimentos ricos em fibras e reduzido conteúdo de gordura, esta deve ser preferencialmente composta por ácidos graxos (AG) de cadeia média a longa, em especial, para o período gestacional, pois a dieta materna, antes da concepção, é de grande importância, já que ela determina o tipo de ácido graxo que se acumulará no tecido fetal. O transporte dos ácido graxos essenciais (AGE) é realizado através da placenta, os quais são depositados no cérebro e retina do concepto. Além disso, ocorre um acúmulo simultâneo nas glândulas mamárias durante essa fase (CAMPOS et al., 2013.

O período gestacional condiciona a necessidades nutricionais aumentadas, pois tem relação com a saúde da mãe e do recém-nascido (RN). Além das recomendações de ganho de peso, as gestantes devem consumir alimentos em variedade e quantidade específicas para atingir as necessidades energéticas e nutricionais (INNIS, 2008).

Os ácidos graxos definidos como AGE não são sintetizados pelo organismo e obtidos através da dieta. Inseridos nesse grupo estão os ácidos nomeados como linoleico (LA 18:2 n-6) e $\alpha$-linolênico (ALA 18:3 n-3), os quais possibilitam síntese aos demais AG e suas famílias, como os ácidos araquidônico (AA, C20:4n-6), eicosapentaenóico (EPA, C20:5n-3) e docosahexaenóico (DHA, C22:6 n-3) (BLOOMINGDALE et al., 2010; ARANCETA; PÉREZ-RODRIGO, 2012).

Outra classificação está relacionada ao tamanho e o número de instauração da cadeia carbônica, assim os ácidos graxos polinsaturados (AGPI) têm cadeia longa caracterizada pela localização da insaturação a partir do terminal metil, o que define a nomenclatura ômega ( $\omega$ ou n), os representantes são as famílias n3, n6 e n9, representadas pelos ácidos linolênico, linoleico e oleico, respectivamente. Os ácidos graxos poli-insaturados apresentam as insaturações separadas por um carbono metilênico $\left(\mathrm{CH}_{2}\right)$ (PERINI et al., 2010). Nessa perspectiva, surgiram os alimentos funcionais, ricos em AGPI associados com a incorporação de melhores hábitos alimentares.

$E$, dentre os alimentos que apresentam em sua composição nutrientes e compostos bioativos devido ao alto teor de lipídeos insaturados, está a linhaça (Linum usitatissimun), fonte de n-3, fibras e lignanas, podendo ser consumida na forma de farinha ou óleo.

A alimentação humana corretamente balanceada deve atender a uma relação ótima entre n-6 e n-3 de 4:1, porém o ritmo de vida atual, muitas vezes, não permite uma alimentação rica e bem combinada, baseada em alimentos criteriosamente selecionados (SHERRY; OLIVER; MARRIAGE, 2015).

Outras relações dietéticas de AGPI n-6/n-3 devem estar na faixa entre 3:1 a 5:1, embora as dietas ocidentais apresentem elevados teor de AGPI n6, e a relação entre eles de 10 a 25:1 podem comprometer sua utilização e biodisponibilidade (HEATON et al., 2013). No Brasil, devido ao elevado consumo de feijão e arroz, e limitado de peixes, a recomendação para a ingestão de AGPI n-3 é maior.

Entre os AGE, o ácido docosahexaenóico (DHA; C22:6 n3), por seu papel essencial no funcionamento normal da célula cerebral, do sistema nervoso central e sistema visual, especialmente dos recém-nascidos, assume grande importância dietética e fisiológica. Também identificado como ácidos graxos polinsaturados de cadeia longa atua no organismo para as funções de aprendizagem, cognição e memória.

O depósito de DHA na retina e no córtex cerebral do feto ocorre principalmente no último trimestre de gestação e nos primeiros seis meses de vida extra-uterina, podendo se estender 
até os dois primeiros anos de vida (KARR; ALEXANDER; WINNINGHAM, 2011). Caso receba uma alimentação com aporte adequado de AGE, a mãe poderá oferecer ao feto a quantidade necessária para um bom desenvolvimento do sistema nervoso e visual. Ademais, a própria gestação caracteriza-se por período em que geralmente há a deficiência desses elementos, devendo a gestante ingeri-los em sua dieta para satisfazer não só as necessidades do concepto como também as suas (JIMENEZ et al., 2015; TORRES; TRUGO, 2009).

A necessidade de incrementar AGE na alimentação de gestantes deve-se principalmente ao consumo inadequado de alimentos fontes desses nutrientes na dieta; como suplementos alimentares, estão os óleos de peixes e/ou derivados. No entanto um dos fatores limitante é o alto custo dessas substâncias, inviabilizando a utilização por gestantes pertencentes a classes econômica menos favorecida (OLIVEIRA et al., 2015; BOKOR et al., 2010). Surge assim a necessidade de estudar alimentos ricos em AGE, citando o óleo de linhaça dourada (Linum usitatissimun L.), que tem baixo custo e pode ser acessível a todas as classes sociais

\section{MATERIAIS E MÉTODOS}

Este é um estudo clínico randomizado, realizado em um hospital universitário no município de Campo Grande, no período entre janeiro/2012 a novembro/2013 autorizado pelo CEP/UFMS, protocolo n. 2057. Participaram deste estudo 34 gestantes de feto único, com idade entre 18 anos a 30 anos, que estavam no início do terceiro trimestre de gestação (26a semana gestacional), sem histórico de abortos ou partos prematuros de outros filhos e uso de drogas ilícitas e lícitas, após assinarem o Termo de Consentimento Livre e Esclarecido.

Foram excluídas pacientes que não concluíram o acompanhamento no ambulatório de ginecologia e obstetrícia do referido Hospital Universitário (HU) ou que não finalizaram todas as etapas de ingestão das diferentes formas de oferta do $n-3$.

As gestantes foram selecionadas através de sorteio aleatório em três grupos: Grupo controle = composto por gestantes que não receberam nenhum suplemento alimentar; Grupo ômega = composto por gestantes que receberam duas cápsulas de n-3 contendo 180 mg de DHA e 270 mg de EPA por cápsulas gelatinosas ao dia; e o Grupo linhaça = composto por gestantes, que receberam, diariamente, duas colheres de sopa (30g) de óleo de linhaça dourada, duas vezes ao dia, junto com as principais refeições, até um mês após o nascimento do RN. As dosagens estabelecidas de ingestão entre as capsulas e óleo se equivalem em quantidade de dos princípios ativos DHA e EPA.

A coleta de amostra de sangue venoso materno no volume de $1 \mathrm{~mL}$ foi realizada antes do consumo e até um mês. As amostras foram encaminhadas para análises de quantificação e determinação da composição dos constituintes lipídicos circulantes.

Nos laboratórios do Departamento de Tecnologia de Alimentos e Saúde Pública do Centro de Ciências Biológicas e da Saúde (CCBS), as amostras de sangue foram transesterificadas de acordo com procedimento método de Lepage-Roy, em seguida pasteurizadas e centrifugadas e redução de $0,1 \mathrm{~mL}$ de sangue e acrescidas da mistura $2 \mathrm{~mL}$ benzeno-metanol (1:4) sob agitação, com posterior adição de 0,2 $\mathrm{mL}$ de cloreto de acetila. Submetido então em banho de água a $100^{\circ} \mathrm{C}$ por 60 minutos, e ao resfriamento, adicionado $5 \mathrm{~mL}$ de carbonato de potássio a $6 \%$ sob agitação e centrifugado a 3.500 rpm por 10 minutos. O sobrenadante foi seco em nitrogênio e ressuspenso a $300 \mu \mathrm{L}$ de diclorometano, contendo $100 \mathrm{ng} / \mu \mathrm{L}$ de C23:0, como padrão interno. 
No Departamento de Química do Centro de Ciências Exatas e Tecnológicas (CCET), o material foi cromatografado por CG (Shimadzu, modelo GC-2010) com detector de ionização de chama, injetor "Split/Splitless" e coluna capilar de sílica fundida com fase estacionária de polietilenoglicol (Carbowax 20M, 30 m x 0,25 mm, Quadrex), para determinações dos ácidos graxos DHA e EPA. As condições cromatográficas para injeção foram estabelecidas num gradiente de aquecimento de escalonado entre $80^{\circ}, 120^{\circ}$ e $240^{\circ} \mathrm{C}$, até a temperatura de detecção em $250^{\circ} \mathrm{C}$ num fluxo de $1 \mathrm{~mL} / \mathrm{min}$. e volume da injeção $1 \mu \mathrm{L}$.

A identificação dos ácidos graxos foram realizadas por comparação com os tempos de retenção dos padrões de ésteres metílicos (SUPELCO, F.A.M.E. mixC12:0 a C24:0, Sigma-Aldrich), quantificando-os através da normalização de área e expressando os resultados em percentual de área de cada ácido graxo em relação à área total destes e aplicado um fator FID de 0,956.

Os dados quantitativos referentes aos conteúdos de LA, ALA, AA, EPA e DHA foram submetidos ao teste ANOVA de uma via, seguido pelo pós-teste de Tukey. A avaliação da correlação linear entre a concentração desses ácidos graxos tanto em conjunto como em cada grupo em separado, foi realizada por meio do teste de correlação linear de Pearson e do teste de regressão linear. A análise estatística foi realizada utilizando-se o software SPSS, versão 20.0, considerando um nível de significância de 5\%.

\section{RESULTADOS E DISCUSSÃO}

A avaliação dos níveis de ácidos graxos em amostras de sangue materno nos períodos antes e após a suplementação revela que houve diferenças entre os conteúdos totais de cada grupo, e também quando comparados entre si. Observando os grupos definidos como controle, ômega e linhaça, é possível afirmar que a análise cromatográfica dos conteúdos específicos e seus teores de ácidos graxos sofreram modulação metabólica direta de acordo com o tipo de fonte oferecida (Quadro 1).

Quadro 1- Conteúdo de ácidos graxos em gramas por $100 \mathrm{~mL}$ nas amostras de sangue de 34 gestantes, com idade entre 18 a 30 anos, dos grupos controle, ômega e linhaça nos períodos anterior e após a intervenção

\begin{tabular}{|c|r|r|r|r|r|r|}
\hline \multirow{2}{*}{ Grupos } & \multicolumn{7}{|c|}{ Ácidos graxos } \\
\cline { 2 - 7 } & Oleico & ARA & \multicolumn{1}{c|}{ LA } & \multicolumn{1}{c|}{ ALA } & EPA & DHA \\
\hline \multirow{2}{*}{ Pré } & & & & & & \\
\hline \multirow{2}{*}{ Controle } & 26,42 & 17,29 & 33,12 & 1,02 & 0,00 & 1,83 \\
& $\pm 0,7^{\mathrm{a}}$ & $\pm 1,3^{\mathrm{a}}$ & $\pm 1,4^{\mathrm{a}}$ & $\pm 0,15^{\mathrm{b}}$ & $\pm 0,00^{\mathrm{a}}$ & $\pm 0,11^{\mathrm{a}}$ \\
\hline \multirow{2}{*}{ Ômega } & 27,62 & 12,84 & 32,66 & 0,91 & 0,09 & 1,93 \\
& $\pm 0,66^{\mathrm{a}}$ & $\pm 3,34^{\mathrm{a}}$ & $\pm 1,61^{\mathrm{a}}$ & $\pm 1,30^{\mathrm{b}}$ & $\pm 0,09^{\mathrm{a}}$ & $\pm 0,32^{\mathrm{a}}$ \\
\hline \multirow{2}{*}{ Linhaça } & 34,87 & 1,93 & 20,51 & 2,28 & 0,13 & 0,39 \\
& $\pm 6,12^{\mathrm{a}}$ & $\pm 0,55^{\mathrm{b}}$ & $\pm 6,61^{\mathrm{a}}$ & $\pm 0,46^{\mathrm{a}}$ & $\pm 0,11^{\mathrm{a}}$ & $\pm 0,14^{\mathrm{b}}$ \\
\hline Pós & & & & & & \\
\hline \multirow{2}{*}{ Controle } & 26,83 & 15,88 & 29,68 & 0,74 & 0,18 & 1,03 \\
& $\pm 1,84^{\mathrm{a}}$ & $\pm 0,72^{\mathrm{a}}$ & $\pm 2,56^{\mathrm{a}}$ & $\pm 0,21^{\mathrm{a}}$ & $\pm 0,12^{\mathrm{a}}$ & $\pm 0,16^{\mathrm{a}}$ \\
\hline \multirow{2}{*}{ Ômega } & 26,89 & 12,53 & 31,13 & 0,72 & 0,51 & 2,07 \\
& $\pm 1,65^{\mathrm{a}}$ & $\pm 3,26^{\mathrm{a}}$ & $\pm 1,72^{\mathrm{a}}$ & $\pm 0,05^{\mathrm{a}}$ & $\pm 0,04^{\mathrm{a}}$ & $\pm 0,30^{\mathrm{a}}$ \\
\hline \multirow{2}{*}{ Linhaça } & 14,13 & 10,94 & 23,17 & 3,25 & 0,54 & 0,94 \\
& $\pm 4,56^{\mathrm{b}}$ & $\pm 3,42^{\mathrm{a}}$ & $\pm 7,36^{\mathrm{a}}$ & $\pm 2,58^{\mathrm{a}}$ & $\pm 0,29^{\mathrm{a}}$ & $\pm 0,39$ \\
\hline
\end{tabular}


Atentando para as diferenças individuais encontradas nas amostras de sangue, o grupo controle não apresentou variação quanto ao conteúdo do ácido oleico (18:1 n-9) precursores orgânico para o AA, mantendo-se quase invariável com valores detectáveis de 26,42 $\pm 0,7$ antes e 26,83 $\pm 1,84$, o mesmo foi observado para os conteúdos de EPA; embora tenha havido um aumento dos níveis de 0,00 para $0,18 \pm 0,12$, este não chegou à importância quantitativa, o que sugere uma sinalização à manutenção da via metabólica e não mostra qualquer variação mesmo havendo aumento das demandas e da necessidade fisiológica na gestação. Os demais conteúdos de AA, LA, ALA e DHA apresentaram queda, o que indica a dificuldade de síntese devida à baixa disponibilidade de percursores.

Em relação ao grupo ômega, foi observada uma queda dos níveis do ácido oleico e do LA, houve a manutenção dos níveis do AA e aumento dos percussores da série n-3. Essa condição pressupõe que o excesso de fonte ômega ajuda a estimular a via n-3, no entanto a constância do nível de AA pode ocasionar um entendimento fisiológico para a produção de eicosanoides e de complexos de pró-inflamatórios que vão interferir diretamente no complexo imunológico.

Enquanto o grupo linhaça apresentou resultados mais homogêneos para a maioria dos níveis dos ácidos graxos avaliados, houve ainda uma queda no teor do ácido oleico e colaborando para um aumento subsequente de todos os percursores tanto da série n-3 como n-6. Efetivamente a suplementação favoreceu a rota metabólica esperada para a formação tanto dos intermediários eicosanoides como também para os produtos finais EPA e DHA.

Ao comparar os grupos entre si, é clara a diferença encontrada entre os grupos de estudo na pós-suplementação. O conteúdo de AA foi maior no grupo controle, o que pôde propiciar a maior produção constituintes celulares pró-inflamatórios; contudo, mantendo os valores de EPA e DHA em igualdade, tanto antes como após o tratamento, conforme apresentado na figura 1.

Figura 1 - Gráfico apresentando os resultados referentes à diferença na concentração dos ácidos graxos AA (C20:4n-6), EPA (C20:5n-)3 e DHA (C22:6n-)3, antes e após o tratamento no sangue das mães avaliadas neste estudo.

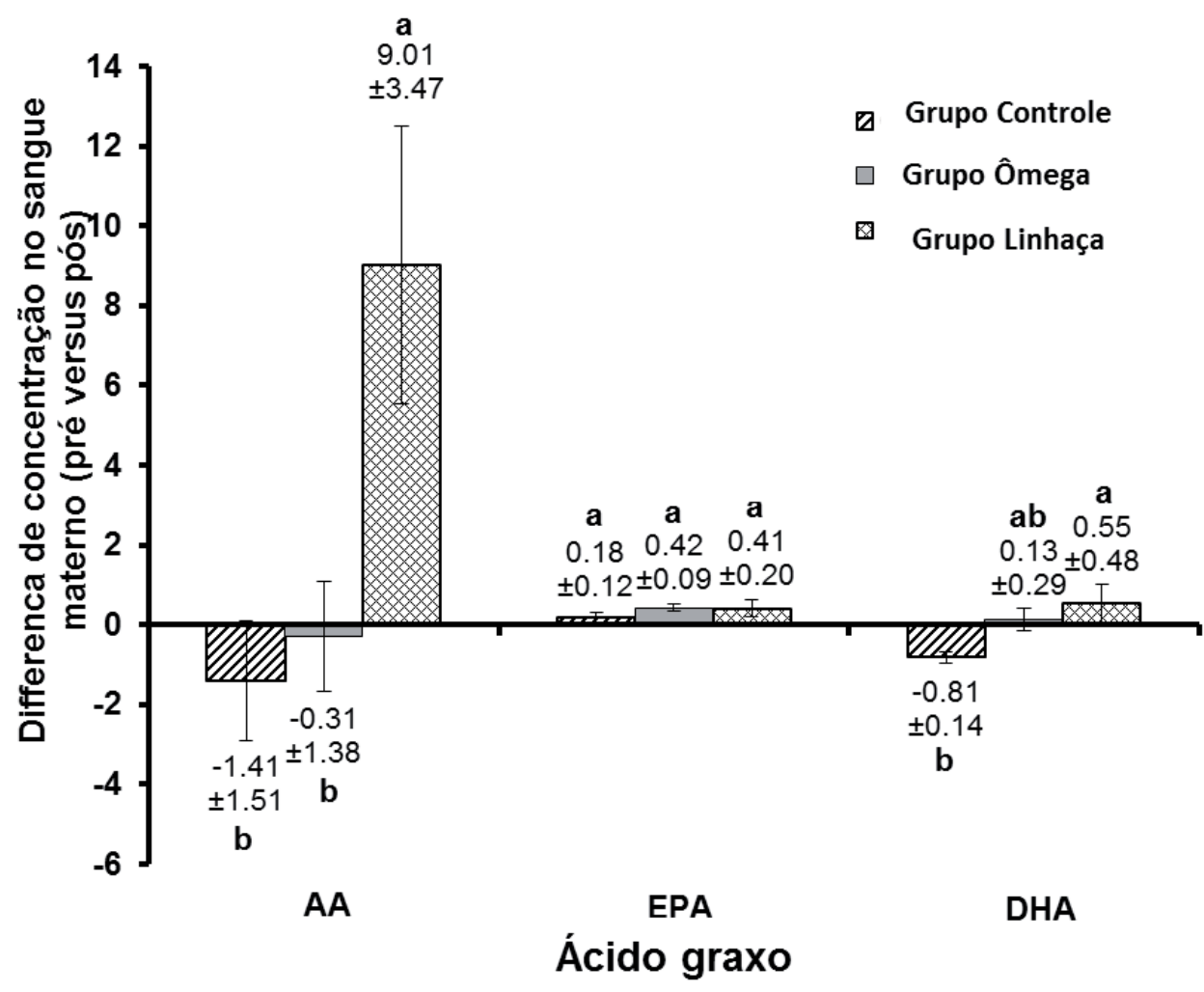

INTERAÇÕES, Campo Grande, MS, v. 19, n. 4, p. 845-853, out./dez. 2018 
Cada coluna representa a média e a barra o erro padrão da média. Letras diferentes nas colunas de cada ácido graxo representam diferença significativa entre os grupos experimentais no pós-teste de Tukey.

O elevado conteúdo do AA (C20:4 n-6) tem relação com a rota de formação e síntese dos percursores lipídicos no organismo e, mesmo que os ácidos graxos da série n-9 (endógeno) e n- 6 (exógena) sigam rotas metabólicas independentes para formação de componentes da membrana e eicosanoides, todos compartilham de intermediários comuns que precisam estar em equilíbrio quantitativo e qualitativo.

Embora o ácido oleico (C18:1 n-9) seja produzido pela introdução de uma dupla ligação no meio da molécula do ácido esteárico entre os carbonos 9 e 10, seu limite de síntese reside na inserção de duplas ligações em direção à extremidade da carboxila, e não em direção à extremidade do grupo metila, característica essa que o difere dos ácidos linoleico e linolênico considerados essenciais. Dentre os seus metabolitos de formação está o EPA um intermediário da rota n-6 que também pode ser formado diretamente do LA, servindo como modulador para o equilíbrio da série n-6 (PERINI et al., 2010).

Assim, a sugestão seria a de que o LA teve preferência na produção $A A$, uma vez que o eicosatrienoico já deveria estar em quantidades suficientes a partir da rota do n-9. E, mesmo sem haver evidências científicas suficientes para estabelecer a Recomendação Média Estimada (EAR), estipula-se que $10 \%$ da ingestão de energia devem ser de ácidos graxos, e que a relação n-6/n-3 em 5:1 fornece uma ótima razão tecidual do AA e EPA, garantida pela ingestão diária de alimentos fontes de ácidos graxos n-6 e n-3 (SIMOPUOLOS et al., 2002).

Metabolicamente não existe interconversão entre as séries n-9, n-6 e n3-, contudo ocorre competição enzimática pelo sítio ativo da enzima, a n-6-dessaturase, que prefere como o $\alpha$-inolênico, ácido linoleico, ácido oleico, segundo a ordem da disponibilidade. Por este motivo, a razão entre a ingestão diária de alimentos fontes de ácidos graxos n-6 e n-3 assume grande importância na nutrição humana, resultando em várias recomendações que têm sido estabelecidas por autores e órgãos de saúde, em diferentes países (MARTIN et al., 2006).

Sob ação das dessaturases o ácido linoleico (n-6) é convertido a AA e o ácido alfa-linolênico (n-3) a EPA. O AA é o precursor das prostaglandinas E2 (PGE2), leucotrienos B4 (LTB4), importantes componentes pró-inflamatórios, e ainda da tromboxana A2 (TXA2), um potente vasoconstritor e agregador plaquetário; enquanto o ácido eicosapentaenóico é convertido em prostaglandinas E3 (PGE3), leucotrieno B5 (LTB5) e a tromboxana A3 (TXA3), com ações potencialmente anti-inflamatórias e antitrombóticas (LOTTENBERG, 2009).

Outros exemplos de transformações é a conversão do ácido esteárico (18:0) em ácido oleico (18:1n-9) ou ácido palmítico (16:0) em palmitoleico (16:1n-7), respectivamente sob a ação de dessaturases (CALDER, 2012).

Indiscutivelmente a dieta interfere no processo de síntese dos ácidos graxos, assim como a razão entre os ácidos graxos das famílias n-6 e n-3. Ao analisar as informações sobre a ingestão alimentar, as gestantes deste estudo relataram a frequência alimentar de frutas e verduras, carne (bovina, ovina, aves e outras), peixe, alimentos fontes de carboidratos, leites e derivados. No grupo linhaça, foi observado um baixo consumo de peixes, apenas (20\%), embora igual ao grupo ômega, a razão entre a ingestão de $n 6$ e $n 3$, também estava inadequada comprometendo o equilíbrio entre os ácidos graxos, sendo o n6 superior. Esse fato também pode ter favorecido o aumento do AA neste grupo além da presença de outros ácidos graxos que preferencialmente seguem a rota do n-9. 


\section{CONSIDERAÇÕES FINAIS}

Até o momento, não estão totalmente elucidados todos os benefícios dos ácidos graxos essenciais e seus metabólitos. Todavia, sabe-se que sua deficiência durante a gestação pode comprometer o desenvolvimento fetal do recém-nascido. Dessa forma, sugere-se implementar estratégias de educação nutricional direcionadas a gestantes e nutrizes, que devem ser estimuladas a consumir alimentos ricos em ácidos graxos monoinsaturados e poli-insaturados, especialmente os da série $n-3$. Sendo assim, a utilização do óleo de linhaça pode ser uma alternativa viável, por ser de baixo custo e de fácil acesso, podendo contribuir com a aquisição de valores nutricionais próximos do esperado.

\section{REFERÊNCIAS}

ARANCETA, J.; PÉREZ-RODRIGO, C. Recommended dietary reference in takes, nutritional goals and dietary guidelines for fat and fatty acids: a systematic review. British Journal of Nutrition, v. 107, Suplemento 2, p. S8-S22, jun. 2012. doi: 10.1017/S0007114512001444

BLOOMINGDALE, A. et al. A qualitative study of fish consumption during pregnancy. The American Journal of Clinical Nutrition, v. 92, n. 5, p. 1234-40, nov. 2010. doi: 10.3945/ajcn.2010.30070

BOKOR, S. et al. Single nucleotide polymorphisms in the FADS gene cluster are associated with delta-5 and delta- 6 desaturase activities estimated by serum fatty acid ratios. Journal of Lipid Research, v. 51, n. 8, p. 2325-33, ago. 2010. doi: 10.1194/jlr.M006205

CALDER, P. C. Mechanism so faction of (n-3) fatty acids. The Journal of Nutrition, v. 142, n. 3, p. 592S-9S, mar. 2012.

CAMPOS, A. B. F.; PEREIRA, R. A.; QUEIROZ, J.; SAUNDERS, C. Ingestão de energia e de nutrientes e baixo peso ao nascer: estudo de coorte com gestantes adolescentes. Revista de Nutrição, Campinas, SP, v. 26, n. 5, p. 551-61, set./out. 2013. http://dx.doi.org/10.1590/S1415-52732013000500006.

HEATON, A. E. et al. Does docosahexaenoic acid supplementation in term infants enhance neuro cognitive functioning in infancy? Frontiers in Human Neuroscience, v. 7, artigo 774, p. 1-12, nov. 2013. https://doi. org/10.3389/fnhum.2013.00774

INNIS, S. M. Dietary omega 3 fatty acids and the developing brain. Brain Research, v. 27, n. 1237, p. 3543, out. 2008.

JIMENEZ, Y. E.; MANGANI, C.; ASHORN, P.; HARRIS, W. S.; MALETA, K.; DEWEY, K. G. Breast milk from women living near Lake Malawi is high in docosahexaenoic acid and arachidonic acid. Prostaglandins Leukotrienes and Essential Fatty Acids, n. 95, p. 71-8, abr. 2015. doi: 10.1016/j.plefa.2014.12.002

KARR, J. E.; ALEXANDER, J. E.; WINNINGHAM, R. G. Omega-3 polyunsaturated fatty acids and cognition through out the life span: a review. Nutritional Neuroscience, v. 14, n. 5, p. 216-25, set. 2011. doi: 10.1179/1476830511Y.0000000012

LEPAGE, G.; ROY, C. C. Direct transesterification of all classes of lipids in a one- stepreaction. Journal of Lipid Research, v. 27, n. 1, p. 114-20, ja. 1986.

LOTTENBERG, A. M. P. Importância da gordura alimentar na prevenção e no controle de distúrbios metabólicos e da doença cardiovascular. Arquivos Brasileiros de Endocrinologia \& Metabologia, São Paulo, v. 53, n. 5, p. 595-607, jul. 2009.

MARTIN, C. A. Trans polynsaturated fatty acid contents in Brazilian refined soybean oil. Analytical Sciences, V. 22, n. 4, p. 631-3, abr. 2006.

OLIVEIRA, F. B.; MIRANDA, A. S.; VIANA JÚNIOR, N. M.; SANTANA, R. F. Qualidade microbiológica de farinhas de linhaça dourada e marrom. UNOPAR Científica, Ciências Biológicas e da Saúde, Londrina, PR, v. 17, n. 3, p. 173-80, jul. 2015. 
PERINI, J. A. L. et al. Omega-3 and omega- 6 polyunsaturated fattyn acids: metabolism in mammalsand immune response. Revista de Nutrição, Campinas, SP, v. 23, n. 6, p. 1075-86, nov./dez. 2010. http://dx.doi. org/10.1590/S1415-52732010000600013

SIMOPOULOS, A. P. Omega-3 fatty acids in inflammatory and autoimmune diseases. Journal of the American College of Nutrition, v. 21, n. 6, p. 495-505, dez. 2002.

SHERRY, C. L.; OLIVER, J. S.; MARRIAGE, B. J. Docosahexaenoic acid supplementation in lactating women increases breast milk and plasma docosahexaenoic acid concentrations and alters infant omega 6:3 fatty acid. Prostaglandins Leukot Essent Fatty Acids, v. 95, p. 63-9, abr. 2015. https://doi.org/10.1016/j. plefa.2015.01.005

TORRES, A. G.; TRUGO, N. M. F. Evidence of inadequate docosahexaenoic acid status in Brazilian pregnant and lactating women. Revista de Saúde Pública, São Paulo, v. 43, n. 2, p. 359-68, abr. 2009. http://dx.doi. org/10.1590/S0034-89102009000200018.

\section{Agradecimentos}

A Universidade Federal de Mato Grosso do Sul (UFMS), Universidade Católica Dom Bosco (UCDB), Conselho Nacional de Pesquisa (CNPq), Fundação de Suporte para o Ensino, Ciência e Tecnologia do Estado do Mato Grosso do Sul (FUNDECT).

\section{Sobre os autores:}

Leila Simone Foerster Merey: Doutora em Saúde e Desenvolvimento na Região Centro-Oeste pela Universidade Federal de Mato Grosso do Sul (UFMS). Mestre em Saúde e Desenvolvimento na Região Centro Oeste pela UFMS. Especialista em Ativação de Processos de Mudança na Formação Superior de Profissionais de Saúde pela Fundação Oswaldo Cruz (FIOCRUZ). Especialista em Fisioterapia em Pneumologia do Departamento de Medicina, da Universidade Federal de São Paulo (Escola Paulista de Medicina- UNIFESP). Graduada em Fisioterapia pela Universidade Católica Dom Bosco (UCDB). Atua como professora Adjunta III da UFMS- Curso de Fisioterapia. Possui experiência na área da Saúde, Formação e Fisioterapia, atuando principalmente nos seguintes temas: Cuidado Integral à Saúde da Criança e do Adolescente. E-mail: leilaufms@gmail.com

Durval Batista Palhares: Pós-Doutor na Case Western Reserve University- RBCH, Cleveland OHIO/USA. Mestre e Doutor em Pediatria pela Faculdade de Medicina da USP de Ribeirão Preto. Graduado em Medicina pela Universidade Federal do Paraná (UFPR), residência em pediatria pela mesma universidade. Faz parceria em projeto de pesquisa da Fundação de Apoio à Universidade Federal do Rio Grande do Sul. É professor titular da UFMS, Departamento de Pediatria, desde 2005. Tem experiência na área de Medicina, com ênfase em Pediatria- Neonatologia, atuando principalmente nos seguintes temas: Estudo do Recém-Nascido Pré-Termo, leite humano evaporado, leite humano e leite humano de banco, aditivo de leite humano liofilizado. Acompanha o Centro de Infusão de Doenças Lisossômicas e tem parceria com a UFRG com projeto pelo CNPq. Está envolvido num estudo do paciente com FOP (fibrodisplasia ossificante progressiva), junto com o Centro de Desenvolvimento de Modelos Experimentais em Medicina e Biologia - EPM/São Paulo. Orienta mestrado e doutorado nos Programas de Pós-Graduação em Saúde e Desenvolvimento na Região Centro-Oeste e em Doenças Infecciosas e Parasitárias da UFMS.

E-mail: dbpalhares@hotmail.com 
Karla Rejane de Andrade Porto: Doutora em Biotecnologia e Biodiversidade pela Rede Pró CentroOeste, Universidade Federal de Mato Grosso do Sul (UFMS). Mestre em Química e Biotecnologia pela Universidade Federal de Alagoas (UFAL). Graduada em Nutrição pela UFAL. Tem experiência na área de Nutrição, com ênfase em Bioquímica da Nutrição e Química de alimentos, atuando em pesquisa com química de produtos naturais, bioensaios e na inovação com tecnologia de alimentos. E-mail: portokra@gmail.com

Karla de Toledo Candido Muller: Doutora e Mestre pelo programa Saúde e Desenvolvimento da Região Centro-Oeste- Saúde e Sociedade da UFMS. Mestre em Ciências Fisiológicas- Fisiologia do esforço pela UNOESTE. Especialista em Ativação do processo de mudanças na formação superior de profissionais de saúde- EAD/ENSP-FIOCRUZ. Graduada em Fisioterapia pela UNOESTE. Professora universitária desde 1997, com experiência na área de Fisioterapia com ênfase em epidemiologia em saúde e em saúde da criança nos diferentes ciclos de vida e níveis de atenção em saúde. E-mail: rf5362@ucdb.br 
